\title{
An Experimental Study of Whirling Characteristics of Gear-Pinion Rotor System
}

\author{
K. V. S. Seshendra Kumar ${ }^{1, *}$, B. S. K. SundaraSiva Rao \\ ${ }^{1}$ Department of Industrial Production Engineering, GITAM Institute of Technology, Gitam University, Visakhapatnam, 530045, India \\ ${ }^{2}$ Department of Mechanical Engineering, Andhra University College of Engineering, Visakhapatnam, 530003, India
}

\begin{abstract}
Geared rotor system analysis is a very challenging problem because of the complicated dynamic behaviour of composite rotors. For example, the whirling motion and critical speed of the system has to be found by considering all the rotors in the system as well as interactions between them, which makes the solution process as well as proper interpretation of the solution extremely complicated. Complex variable approach, which is proposed for the analysis of a single rotor system, is very powerful for this purpose. The approach is expanded to the analysis of combined rotor system to apply it to the gear system dynamics. A finite-element model of a geared rotor system on flexible shaft bearings has been developed. The model includes the bearing stiffness and shaft flexibility taken in two mutually perpendicular directions and the stiffness of the gear mesh. It is shown that the lateral vibrations have considerable effect when the natural frequencies of the lateral vibration and torsional vibration are close to each other. The whirling response of the system is studied for strong lateral-torsional coupling, thereby; the nature of the coupling effect is discussed.
\end{abstract}

Keywords Rotor Dynamics, Lateral-Torsional Coupling, Bearing Stiffness, Shaft Flexibility, Finite Element Method

\section{Introduction}

In the past works, the effects of mass imbalance and eccentricity of the gear on the shaft were considered in various geared rotor dynamic models, virtually neglecting the actual dynamics of gear mesh. Hamad and Seireg[1] studied the whirling of geared rotor systems supported on hydrodynamic bearings. Torsional vibrations were not considered in this model and the shaft of the gear was assumed to be rigid. Iida et.al.,[2] considered the same problem by assuming one of the shafts to be rigid and neglecting the compliance of the gear mesh and obtained a three degree of freedom model that determined the first three vibration modes and the forced vibration response due to unbalance and the geometric eccentricity of one of the gears. They also showed that their theoretical results confirmed experimental measurements. Later Iida.et.al.,[3] applied their model to a larger system consisting of three shafts coupled by two gear meshes. Hagiwara, Iida and Kikuchi[4] [developed a simple model that included the transverse flexibilities of the shafts by using discrete stiffness values that took the damping and compliances of the journal bearings into account and that assumed the mesh stiffness to be constant. With their model they studied the forced response of geared shafts due to unbalance

* Corresponding author:

venkat_seshendra@yahoo.co.in (K.V.S.Seshendra Kumar)

Published online at http://journal.sapub.org/mechanics

Copyright (C) 2012 Scientific \& Academic Publishing. All Rights Reserved and run out errors.

The backlash detection and its influence in geared systems has been studied by N Sarkar et al[5]. M Ambili and A Fregolent[6] determined modal parameters of spur gear system using Harmonic Balance Method. Study of designing compact spur gears taking into consideration of tooth stress and dynamic response was done by PH Lin et al.[7] Dynamic behaviour of Spur gears to varying mesh stiffness and tooth error has been studied by J Kuan and A Lin[8]. A mathematical model for gear geometry error and mounting error has been developed by P Velex and M Maatar[9]. S Theodassiades and $S$ Nastiavas[10] studied non-linear behaviour of gear system with backlash and varying stiffness. They also studied non-linear influence of bearings characteristics on gear pair system[11]. Modal Analysis of compliant multibody gear systems has been analysed by $\mathrm{H}$ Vinayak and $\mathrm{R}$ Singh[12].

The influences of non-uniform gear speed, and timevariant meshing stiffness on dynamic behaviour using Finite Element Modelling was investigated by Y. Wang et al.[13]. Effect of shaft flexibility and non-linear vibration in gear pair was studied by G Litak and M Friswell[14]. Method to calculate dynamic gear tooth force and bearing forces and its effects were studied by L Vedmar and A Anderson[15]. Y Cheng and $\mathrm{T} \operatorname{Lim}[16]$ derived exact gear geometry from manufacturing parameters and used it to study dynamic behaviour of hypoid gears. Shen et al.[17] performed coupled torsional-lateral vibration of the unbalanced rotor system with external excitations through numerical simulation. 


\section{Finite Element Model of Gear Pair System}

In the present work, a finite element model is developed for the dynamic analysis of geared rotor system considering the effect of bearing flexibility, which is usually neglected in simple gear dynamics models, on the dynamics of the system. In many gear dynamics analyses, the effect of the lateral vibration has been ignored in modelling the system with the underlying assumption that the effect of the lateral deflection in a typical gear system is negligible compared to that of the torsional deflection.

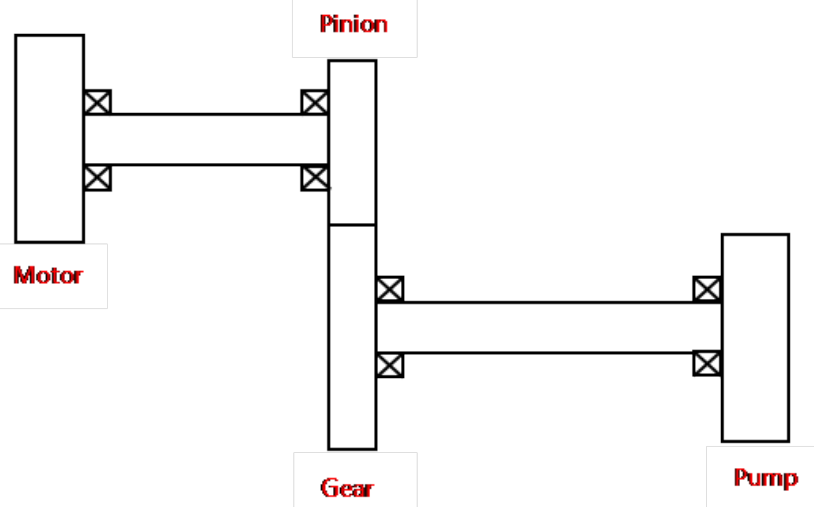

Figure 2.1. Mathematical model of the geared rotor system

This assumption may not be valid in some configurations such as overhung type gears rotating at a high speed, in which therefore the whirling resonance speed occur within the operating frequency range. To understand the effect of possible interactions between the lateral and torsional responses, a simple gear system is considered in this study whose parameters are chosen so that its lateral and torsional natural frequencies are close to each other.

\subsection{Equation of Motion in Real Description}

The system consists of two gears (pinion, $P$ and gear, $G$ ) in mesh and driven by a motor $M$ and driving a load $L$. The shafts on which gears are mounted have two translational degrees of freedom each, one in horizontal direction ( $\mathrm{Z}$ direction) and other in vertical direction ( $Y$ direction). The gears, motor and load have torsional degree of freedom. Therefore, there are four degrees of freedom $\left(x_{P}, y_{p}, x_{g}\right.$, and $\left.\mathrm{y}_{\mathrm{g}}\right)$ in the lateral direction and four degrees of system $\left(\theta_{\mathrm{m}}, \theta_{\mathrm{p}}\right.$, $\theta_{\mathrm{g}}$, and $\left.\theta_{1}\right)$ in the torsional direction in the system. The equation of motion is obtained by an eight by eight matrix equation as given in equation 2.1 .

The external forces considered in the above equation are: $\left(\mathrm{T}_{\mathrm{g}}\right)$

a. Torques on motor $\left(\mathrm{T}_{\mathrm{m}}\right)$, load $\left(\mathrm{T}_{1}\right)$, pinion $\left(\mathrm{T}_{\mathrm{p}}\right)$ and gear

b. Unbalance masses $U_{p}$ and $U_{g}$ acting on pinion and gear respectively. $\psi$ defines the phase angle between the two unbalance masses in the pinion and gear. These unbalance forces act in the lateral directions, however can cause torsional responses because the equations are coupled in two directions.

Once the system equation is set up this form, positive frequency solutions indicate whirling and rotational motion in the forward direction (counter-clockwise direction) and negative frequency solutions indicate motions in the backward direction (clockwise direction).

$$
\begin{aligned}
& {\left[\begin{array}{cccccccc}
m_{p} & 0 & 0 & 0 & 0 & 0 & 0 & 0 \\
0 & m_{g} & 0 & 0 & 0 & 0 & 0 & 0 \\
0 & 0 & m_{p} & 0 & 0 & 0 & 0 & 0 \\
0 & 0 & 0 & m_{g} & 0 & 0 & 0 & 0 \\
0 & 0 & 0 & 0 & I_{p} & 0 & 0 & 0 \\
0 & 0 & 0 & 0 & 0 & I_{g} & 0 & 0 \\
0 & 0 & 0 & 0 & 0 & 0 & J_{m} & 0 \\
0 & 0 & 0 & 0 & 0 & 0 & 0 & J_{l}
\end{array}\right]\left[\begin{array}{c}
\ddot{y}_{p} \\
\ddot{y}_{g} \\
\ddot{x}_{p} \\
\ddot{x}_{g} \\
\ddot{\theta}_{p} \\
\ddot{\theta}_{g} \\
\ddot{\theta}_{m} \\
\ddot{\theta}_{l}
\end{array}\right]_{+}} \\
& {\left[\begin{array}{cccccccc}
K_{y}+K_{m} & -K_{m} & 0 & 0 & { }_{p} K_{m} & -r_{g} K_{m} & 0 & 0 \\
-K_{m} & K_{y}+K_{m} & 0 & 0 & -r_{p} K_{m} & r_{g} K_{m} & 0 & 0 \\
0 & 0 & K_{x} & 0 & 0 & 0 & 0 & 0 \\
0 & 0 & 0 & K_{x} & 0 & 0 & 0 & 0 \\
r_{p} K_{m} & -r_{p} K_{m} & 0 & 0 & r_{p}^{2} K_{m}+K_{t} & -r_{p} r_{g} K_{m} & -K_{t} & 0 \\
-r_{g} K_{m} & { }_{g} K_{m} & 0 & 0 & -r_{p}{ }^{r} K_{m} & { }^{2} K_{g}{ }_{m}+K_{t} & 0 & -K_{t} \\
0 & 0 & 0 & 0 & -K_{t} & 0 & K_{t} & 0 \\
0 & 0 & 0 & 0 & 0 & -K_{t} & 0 & K_{t}
\end{array}\right]\left[\begin{array}{c}
y_{p} \\
y_{g} \\
x_{p} \\
x_{g} \\
\theta_{p} \\
\theta_{g} \\
\theta_{m} \\
\theta_{l}
\end{array}\right]=} \\
& {\left[\begin{array}{c}
U p \Omega^{2} \operatorname{Cos} \Omega t \\
U_{g} N^{2} \Omega^{2} \operatorname{Cos}(N \Omega t+\psi) \\
U p^{2} \operatorname{Sin} \Omega t \\
U_{g} N^{2} \Omega^{2} \operatorname{Sin}(N \Omega t+\psi) \\
T_{p} \\
T_{g} \\
T_{m} \\
T_{l}
\end{array}\right]}
\end{aligned}
$$

\section{Whirling Characteristics of Gear Pinion System}

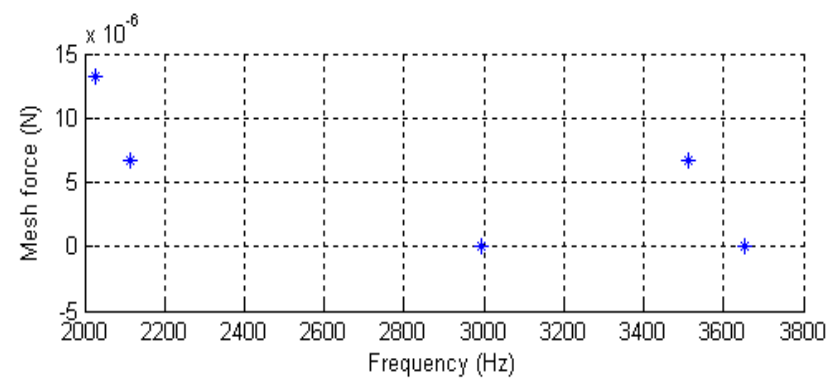

Figure 3.1. Whirling Characteristics of Pinion at frequency in-between natural frequencies - Unbalanced Pinion 
Table 3.1. Summary of whirling characteristics for different inputs

\begin{tabular}{|c|c|c|c|c|c|}
\hline & & \multicolumn{4}{|c|}{ Frequencies in $\mathrm{Hz}$} \\
\hline \multicolumn{2}{|l|}{ Case } & 2028 & 2113 & 3513 & 3656 \\
\hline \multirow[t]{2}{*}{ Unbalance in pinion } & Pinion whirl & No change & $\begin{array}{c}\text { Change of direc- } \\
\text { tion }\end{array}$ & $\begin{array}{c}\text { Change of direc- } \\
\text { tion }\end{array}$ & $\begin{array}{c}\text { Change of direc- } \\
\text { tion }\end{array}$ \\
\hline & Gear whirl & \multicolumn{4}{|c|}{ No Whirling Present } \\
\hline \multirow[b]{2}{*}{ Unbalance in gear } & Pinion whirl & \multicolumn{4}{|c|}{ No Whirling Present } \\
\hline & Gear Whirl & $\begin{array}{l}\text { Change of direc- } \\
\text { tion }\end{array}$ & $\begin{array}{l}\text { Change of direc- } \\
\text { tion }\end{array}$ & No change & $\begin{array}{l}\text { Change of direc- } \\
\text { tion }\end{array}$ \\
\hline \multirow{2}{*}{$\begin{array}{l}\text { External Torque on } \\
\text { motor } \\
\end{array}$} & Pinion whirl & \multicolumn{4}{|c|}{ No Whirling Present } \\
\hline & Gear whirl & \multicolumn{4}{|c|}{ No Whirling Present } \\
\hline
\end{tabular}

The whirling characteristics of gear pinion rotor system are determined considering the mass unbalances on pinion, gear and external torque acting on the system. The figure 3.1 represents the whirling characteristics of the pinion due to its mass unbalance.

Reversal of the whirling direction indicates the existence of the resonance frequency at the frequency point. These reversals occur at $2026 \mathrm{~Hz}$ and $2115 \mathrm{~Hz}$ in the pinion if the unbalance is in the pinion. These frequencies are whirling frequencies of the pinion, which acts essentially as a Jeffcott rotor supported by orthotropic supports. The anisotropy of the support is due to the effect of the gear mated to the pinion.

No whirling occurs in gear when unbalanced mass is present on pinion. This can be explained by the fact that force transmission is only along the mesh line. This can cause vibrations only in $\mathrm{Y}$ direction (mesh direction) exerting only the linear force; therefore does not cause any vibrations in $\mathrm{X}$ direction. This fact is also confirmed by the bearing reactions in the system when the unbalance is present on pinion.

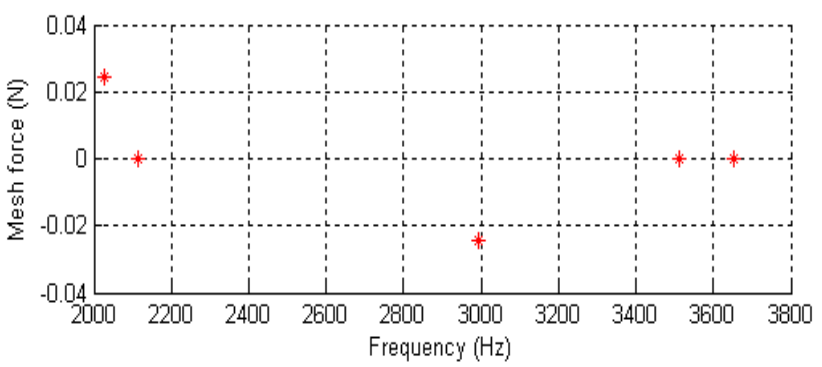

Figure 3.2. Whirling Characteristics of Gear at frequency in-between natural frequencies - Unbalanced Gear

Figure 3.2 represent the whirling characteristics of the gear due to its mass unbalance. When the unbalance is present on gear, the whirling occurs only on gear and not on pinion. As stated before, change of direction of whirling indicates existence of natural frequency.

In this case, change of direction occurs at 3511 and 3655 $\mathrm{Hz}$. These frequencies are whirling frequencies of the gear, which acts essentially as a Jeffcott rotor supported by an orthotropic supports. The anisotropy of the support is due to the effect of the pinion mated to the gear. Similar to case of unbalanced pinion, unbalanced mass on gear does not cause any whirling response in the pinion. The reason as explained earlier, is that is force transmitted (or interaction between gear and pinion) is only through mesh.

\section{Summary and Conclusions}

In the present work, the whirling characteristics of geared rotor system for combined torsional-lateral vibrations have been carried out. In the analysis, transverse and torsional vibrations of the shafts and the transverse vibrations of the bearings have been considered. It has been demonstrated that the lateral motions interact significantly with torsional degrees of freedom if the resonance frequencies are similar. For the system under study, this interaction occurs around 26,000 $\mathrm{rad} / \mathrm{s}$ where two close critical speeds exist instead of one as found by torsional only system. Comparison of the resulting mesh forces in two systems when the motor torque varies with amplitude of $1 \mathrm{~N}-\mathrm{m}$ is applied on the motor for the torsion-lateral motion combined system and the torsion only system. The analysis certainly shows that the lateral whirling motions of the rotors (that model the gear and pinion) and torsional motions of the gears interact with each other. The degree of interaction depends on the proximity of the natural frequencies of the lateral and torsional motions. Neglecting the coupled effect in design can have serious effects on the estimation of the performance of the system if their frequencies are close to one another.

\section{REFERENCES}

[1] Hamad.B.M and Seireg.A, 1980, Simulation of whirl in teraction in pinion-gear systems supported on oil film bearings. Journal of Engineering Power, 102,508-510.

[2] Iida et.al. 1980, Coupled Torsional-flexural vibration of a shaft in a geared system of rotors, Japanese society of mechanical Engineers.23, 2111-2114.

[3] Iida et.al. 1984, Coupled torsional-flexural vibration of a shaft in a geared system, International conference on vibration in rotating machinery 3rd Mechanical Engineering publications, London,

[4] Hagiwara.N, Ida.M and Kikuchi.K, 1981, Forced vibration of a pinion gear system supported on journal bearings, Proceedings of International symposium of gearing and power transmissions JSME, Tokyo, 85-90. 
[5] Sarkar.N, Ellis.R.E and Moore.T.N, 1997, Backlash Detection in Geared Mechanism: Modeling, Simulation, and Experimentation, Mechanical Systems and Signal Processing, 11( 3), 391-408.

[6] Amabili.M and Fregolent.A, 1998, A Method to Identify Modal Parameters and Gear Errors by Vibrations of a Spur Gear Pair, Journal of Sound and Vibration, 214(2),339-357.

[7] Lin.P.H, Lin.H.H, Oswald.F.B and Townsend.D.P, 1998, Using Dynamics Analysis for Compact Gear Design, Design Engineering Technical Conference, 1-8.

[8] Kuan.J.H and Lin.A.D, 2003, Theoretical Aspects of Torque Responses in Spur Gearing due to Mesh Stiffness Variation, Mechanical Systems and Signal Processing,17( 2),255-271.

[9] Velex.P, and Maatar.M, 1996, A Mathematical Model for Analyzing the Influence of Shape Deviations and Mounting Errors on Gear Dynamic Behavior, Journal of Sound and Vibration,19(5),629-660.

[10] Theodossiades.S and Nastiavas.S, 2000, Non-linear Dynamics of Gear Pair Systems with Periodic Stiffness and Backlash, Journal of Sound and Vibration, 229(2), 287-301.

[11] Theodossiades.S and Nastiavas.S, 2001, Periodic and Chaotic Dynamics of Motor-driven Gear Pair Systems with Backlash,
Chaos Solitons and Fractal, 12, 2427-2440.

[12] Vinayak.H and Singh.R, 1998, Multi-body Dynamics and Modal Analysis of Compliant Gear Bodies, Journal of Sound and Vibration, 210(2), 171-214.

[13] Wang.Y, Cheung.H.M and Zhang.W.J, 2002, Finite Element Modeling of Geared Multi-body System, Communications in Numerical Methods in Engineering, 18, 765-778.

[14] Litak.G and Friswell. M.I, 2003, Vibration in Gear Systems, Chaos, Solitions and Fractals, 16, 795-800.

[15] Vedmar.L and Andersson.A, 2003, A Method to Determine Dynamic Loads on Spur Gear Teeth and on Bearings, Journal of Sound and Vibration, 267 1065-1084.

[16] Cheng.Y and Lim.T.C, 2001, Vibration Analysis of Hypoid Transmissions Applying an Exact Geometry-Based Gear Mesh Theory, Journal of Sound and Vibration, 240(3), 519-543.

[17] Shen.Y, Jia J.H. Zhao.M. and Jing.J.P, 2007, Coupled Torsional-lateral vibration of the unbalanced rotor system with external excitations. Proceedings of the Institution of Mechanical Engineers, 42, 423-431. 